\title{
Psychosocial Factors Associated With Malaria Care- seeking in Rural Ethiopia
}

Bolanle Olapeju ( $\square$ bolanle.olapeju@jhu.edu )

Johns Hopkins University

\section{Habtamu Tamene}

Johns Hopkins Center for Communication Programs - Ethiopia

Minyahil Ayele

Johns Hopkins Center for Communication Programs - Ethiopia

\section{Simon Heliso}

Johns Hopkins Center for Communication Programs - Ethiopia

\section{Tsega Berhanu}

Johns Hopkins Center for Communication Programs - Ethiopia

Guda Alemayehu

U.S. President's Malaria Initiative, USAID

Nandita Kapadia-Kundu

Johns Hopkins University

\section{Research Article}

Keywords: Care-seeking, Ethiopia, Malaria, Psychosocial

Posted Date: November 30th, 2021

DOI: https://doi.org/10.21203/rs.3.rs-1062042/v1

License: (c) (1) This work is licensed under a Creative Commons Attribution 4.0 International License.

Read Full License 


\section{Abstract}

\section{Background}

Ethiopia's National Malaria Control and Elimination Program aims to diagnose all suspected malaria cases within 24 hours of fever onset and provide prompt treatment for confirmed cases. This study explored psychosocial factors associated with no-, delayed-and prompt- care-seeking among female caregivers of children under five with fever in rural Ethiopia.

\section{Methods}

Household surveys were conducted from 2016-2019 among female caregivers $(N=2453)$ of children under five years old in Oromia; Amhara; Southern Nations, Nationalities, and Peoples Region (SNNPR); and Tigray. Prompt and delayed care-seeking were defined as seeking treatment within $\leq 24$ hours or $>24$ hours of symptom onset respectively. Contextual factors explored included sociodemographic factors, household supply of bed nets, exposure to health messages, and household vulnerability (a measure of financial access to food, shelter, schooling, and medical treatment). Ideational factors included psychosocial factors related to care-seeking (knowledge, self-efficacy, response efficacy, beliefs, involvement in decision-making, and household social support).

\section{Results}

The prevalence of fever among children under five was $18 \%$ (ranging from $9 \%$ in Tigray to $34 \%$ in SNNPR. Overall, $45 \%$ of caregivers of children with fever sought care promptly, while $23 \%$ delayed care-seeking and $32 \%$ sought no care. Prompt care-seeking rates were higher among caregivers with positive attitudes toward prompt care-seeking (48\%), involved in decision-making (48\%) or perceived equitable gender norms in the community (65\%). Caregivers with a high care-seeking ideation had increased odds of prompt care-seeking (aOR: $2.65 ; 95 \% \mathrm{Cl}$ : 1.74-4.02). Significant contextual factors included residence in the Oromia region (aOR: 2.99 ; 95\% Cl:1.40-6.41), caregivers age $35-49$ years (aOR: $0.49 ; 95 \% \mathrm{Cl}$ : $0.26-$ 0.95 ), residence in vulnerable households (aOR: $2.01 ; 95 \% \mathrm{Cl}: 1.28-3.18$ ).

\section{Conclusions}

Among this rural Ethiopian population, prompt care-seeking was low but positively influenced by both ideational and contextual psychosocial factors occurring at the caregiver level. Multi-sectoral interventions at the individual, community, and health facility levels are needed to improve prompt careseeking. These include social behavior change interventions to improve ideation, complemented by health facility interventions to ensure provision of high-quality services and structural interventions to increase educational attainment in these rural settings.

\section{Background}


In 2019, Ethiopia achieved the Global Technical Strategy for Malaria 2020 target of a $40 \%$ reduction in malaria case incidence and reduction in mortality rate[1]. While Ethiopia is characterized by an overall low malaria prevalence rate, over half of Ethiopians remain vulnerable to malaria with 27 million people living in high-transmission zones (more than one case per 1,000 population)[2] and over 250,000 confirmed cases of malaria in 2019[1].

Appropriate management of fever cases, insecticide-treated net (ITN) use, and intermittent presumptive treatment of malaria in pregnancy remain key to malaria control. The National Malaria Control and Elimination Program (NMCEP) has made great strides in reducing malaria burden and charting a path to elimination, including the roll-out of rapid diagnostic testing (RDT) and artemisinin-based combination therapy at the community level. Prompt care-seeking (defined as seeking care within the same day or next day of fever onset) is a key behavior to ensuring proper case management of suspected and confirmed malaria cases.

NMCEP aims to ensure all suspected malaria cases are diagnosed using either RDT or microscopy within 24 hours of fever onset and all households living in malaria-endemic areas have the knowledge, attitudes, and practices necessary for adopting appropriate health-seeking behavior for malaria prevention and control[2]. While the 2015 National Malaria Indicator Survey demonstrated that advice or treatment was sought for half of all children with fever, the number of children of fever for whom care was promptly sought is unknown[3].

Considering NMCEP's objectives and the critical role of prompt care-seeking in ensuring proper diagnosis and treatment of malaria, relevant stakeholders need to understand the factors influencing care-seeking behaviors for children with fever, particularly at the caregiver level. Specifically, to what extent Ethiopian caregivers who seek care promptly may differ from those who delay seeking care and from those who never seek care at all.

Of particular interest is the role of caregivers' psychosocial factors, defined as social, cultural, environmental phenomena, and other influences that may affect their behavior[4].Psychosocial factors play an indubitable role in health and behavior change[5-7]. Recent studies in Ethiopia have explored the psychosocial factors associated with prompt care-seeking[8-11]. A facility-based study of a predominantly adult patient population in the Amhara region revealed that about half of febrile patient participants sought treatment within 24 hours of fever onset, and this was higher among patients who were knowledgeable about malaria prevention and transmission, close to a health center, or had a family size of less than five household members[11].

In Tigray, care-seeking was delayed among low-income patients and those without health insurance[9]. In Dera, northwest Ethiopia, income, community-based health insurance, previous history of malaria infection, decision-making and distance from the facility were determinants of delay in seeking treatment for malaria[10]. In addition, a community based study in Jimma found higher rates of prompt careseeking among Muslim and uneducated respondents[8]. 
However, few studies have specifically explored factors influencing prompt care-seeking among caregivers of febrile children under five years of age. This warrants deeper research, as children under five remain more vulnerable to malaria complications. Community studies demonstrated low levels of caretakers' understanding of malaria in specific localities. Specifically, in the Mandura district of West Ethiopia, a considerable number of caregivers first consulted traditional healers and tried home treatment and thus, sought treatment late[12]. Caregivers' ages, malaria knowledge, perceived susceptibility to malaria, and perceived barrier to seek treatment, and if caregivers lived in rural villages, were important factors in seeking health care[12].

This study seeks to explore the spectrum of prompt care-seeking behavior and associated psychosocial factors among female caregivers of children under five with fever in rural Ethiopia: Oromia; Amhara; Southern Nations, Nationalities, and Peoples Region (SNNPR); and Tigray. Study findings can inform the design of evidence-based community engagement approaches that appropriately target caregivers in these regions and other similar settings.

Several conceptual frameworks have explored psychosocial factors influencing health behavior. As shown in Figure 1, the ideation framework developed by Kincaid serves as the underpinning for this manuscript $[13,14]$. The concept of ideation has proven useful in understanding individual-level psychosocial factors affecting malaria-specific outcomes including ITN use $[15,16]$ and appropriate careseeking[17]. The ideation framework is drawn from various behavioral theories and recognizes that most behavioral decisions are driven by psychosocial factors including cognitive, emotional, and social factors[14]. Cognitive factors include knowledge of disease symptoms; transmission and prevention; and beliefs, values, and attitudes related to proposed actions. Emotional factors include perceived severity and susceptibility to disease, perceived self-efficacy and belief in the efficacy of proposed actions. Social factors include social support, social influence, spousal/partner communication, and personal advocacy.

This study uses the ideation framework to understand the psychosocial factors associated with careseeking among caregivers of febrile children under five. The study explores a limited number of ideational psychosocial factors related to care-seeking (malaria-related knowledge, self-efficacy, response-efficacy, beliefs, decision-making agency, and social support in the household) against the backdrop of overarching contextual psychosocial factors (demographics, physical environment, and access to resources) seen among caregivers in rural Ethiopia.

\section{Methodology}

\section{Study Population}

The data presented in this manuscript are drawn from survey data for the Communication for Health (C4H) project- a five-year (2015-2020) project in Ethiopia funded by the United States Agency for International Development focusing on integrated social and behavior change communication (SBCC) in multiple health areas including malaria [16]. The goal of the $\mathrm{C} 4 \mathrm{H}$ project was to improve health practices 
through standardized SBCC interventions in four major regions of Ethiopia: Amhara, Oromia, Tigray, and SNNPR. The project conducted formative studies, including a baseline survey in 2016 targeting all woredas in the four study regions and a follow-up survey in 2019 assessing the exposure and effectiveness of the interventions among 160 woredas where the interventions had been implemented. The $\mathrm{C} 4 \mathrm{H}$ project study population was women of reproductive ages (15-49 years) who were the primary beneficiaries of the project's social and behavior change interventions. In addition to integrated social and behavior change activities, specific care-seeking interventions implemented by $\mathrm{C} 4 \mathrm{H}$ included a radio drama series and the use of audio-mounted vans to disseminate messages in intervention areas.

\section{Sample size}

The study sample size for both the $\mathrm{C} 4 \mathrm{H}$ baseline, and follow-up surveys were calculated assuming a $5 \%$ type I error and $80 \%$ power to detect a $5 \%$ change from baseline estimate on key project indicators (for example, increasing the proportion of under five children slept under an ITN from baseline values of $43.3-48.3 \%)$. This resulted in a required sample size of 1,555 women of reproductive age. An additional $20 \%$ of the baseline sample size was included for non-response in the follow-up survey.

\section{Sampling strategy and data collection}

This study applied a multi-stage cluster sampling to identify eligible households with women aged 15-49 years. First, $10 \%$ of the project woredas (24 of 240 woredas at baseline and 16 of 160 woredas at endline) were selected using Probability proportionate to size (PPS) sampling, with an equal number of woredas from each of the four regions (Oromia, Amhara, SNNPR, and Tigray). Then, three enumeration areas (EAs), a geographic area consisting of a manageable number of dwelling units (150-200 households) were randomly selected from each woreda using PPS sampling. The study created a list of households with women of reproductive age in each EA and then selected 35 households using a systematic random sampling technique from the list of each EA. The study data collectors interviewed all women aged 15-49 from the eligible households. See Supplemental Table 1 for more details.

\section{Ethical considerations}

The study received ethical approval from the Ethiopian Public Health Institute (EPHI) ethical review committee, Addis Ababa, Ethiopia, and the institutional review board (IRB) of the Johns Hopkins Bloomberg School of Public Health (JHSPH), Baltimore, Maryland, USA (JHSPH IRB \# 00007138 and EPHI-IRB-173-2019). All study procedures were performed in accordance with the Declaration of Helsinki. Informed consent was obtained from all study participants. Participants less than 18 years provided a informed assent after parental consent was obtained.

\section{Data collection}

The study interviewed a total of 4,543 women aged $15-49$ (94\% response rate). Of these, 2,770 ( $92 \%$ response rate) were interviewed at baseline; because the intervention was implemented in fewer communities than the potential number determined at baseline, 1,773 (97\% response rate) were interviewed at follow-up surveys. The questionnaires aimed to collect information on common themes, 
including sociodemographic characteristics, malaria related behavior and psychosocial factors, gender equitable norms, and access to health education messages. The study administered questionnaires in the Amharic, Oromia, and Tigrigna languages. Of the 4,543 women in the dataset, this manuscript focuses on 2,453 women given both the baseline and follow-up surveys who were caregivers of children under five years old.

\section{Data Analysis}

The study measured participants' care-seeking behaviors and psychosocial factors accounting for contextual factors, including demographic characteristics, vulnerability, and gender equitable norms. The survey asked all caregivers, "Has [child's name] been ill with a fever at any time in the last two weeks?" Any care-seeking was defined using the question, "Did you seek advice or treatment for the fever from any source?" This study defined overall care-seeking as "prompt," "delayed," or "none," based on the time elapsed before seeking care.

The key outcome variable was prompt care-seeking for fever; explored by the survey question, "How long after the onset of fever did you seek treatment?" This study defined prompt care-seeking as seeking treatment within 24 hours or less and Delayed care-seeking as seeking treatment more than 24 hours after the onset of fever.

Psychosocial factors explored in this study included ideational factors relevant to care-seeking as well as overarching contextual factors. A limited number of ideational psychosocial factors related to careseeking (knowledge, self-efficacy, response efficacy, beliefs, involvement in decision-making, and social support in the household) were explored as follows:

- Knowledge: The study assessed this by exploring participants' awareness of malaria, signs and symptoms, cause, and prevention measures. Specific questions included the following:

- "Have you ever heard of an illness called malaria?"

- "What signs or symptoms would lead you to think a person has malaria?"

- "What do you think is the cause of malaria?"

- "How can someone protect themselves against malaria?"

- Self-efficacy: This refers to an individual's belief in one's capacity to execute behaviors necessary to produce specific performance attainments[18]. This study assessed participants' self-efficacy for care-seeking and malaria prevention using the following statement: "I can take my child to treatment within 24 hours of onset fevers, and I am able to have children under five years sleep under an ITN each night."

- Response efficacy: This refers to a person's beliefs as to whether the recommended action step will avoid the threat. The study sought to understand if participants understood the benefits gained if they engaged in prompt care-seeking or malaria prevention behavior. This study proposed statements to participants like, "Having my children sleep under an ITN each night will prevent 
malaria," and, "Seeking treatment for my under five children within 24 hours of onset fever improves chances of recovery and survival."

- Attitudes towards care-seeking: This study assessed this using the statement, "I should seek treatment for children under five years within 24 hours of onset of fever." Responses for self-efficacy, response efficacy, and attitudinal questions were recorded on a four-point Likert scale of "Strongly agree," "Agree," "Disagree," and "Strongly disagree."

- Involvement in decision-making: this study explored this using the question, "Who usually makes decisions about health care for yourself: you, your (husband/partner), or you and your husband/partner jointly?" Respondents who noted they made decisions by themselves or jointly with their partners were considered involved in decision making.

- Social support: This study assessed this by asking about the level of spousal support on household chores using the question, "Does your husband help you with household chores like looking after the children, cooking, cleaning the house, and doing other work around the house?" This question served as a proxy for actual spousal support on caregiving.

- Descriptive norms within the community: This study measured caregivers' perceptions regarding gender equitable norms using a 21-item Gender Equitable Men scale adapted for women. The adapted scale includes four sub scales related to physical violence, sexual relationships, reproductive health and disease prevention, and domestic chores and daily life. Responses to all 21 questions were condensed into a composite score and then subdivided into two categories of perceived gender equity: high perceptions of equitable gender norms (based on an inequality score $\leq$ 46) and moderate or low perceptions of equitable gender norms (based on moderate/high inequality score $>46)$.

This study condensed all ideational psychosocial variables into a composite score, referred to as careseeking ideation, ranging from $0-12$ (Cronbach's alpha of 0.7 ). Caregivers with a care-seeking ideation score of 9 or more (greater than the median) were categorized as having a high care-seeking ideation, while those with a score of 8 or less were categorized as having low care-seeking ideation. Supplemental Table 2 summarizes the psychosocial variables used in generating the malaria care-seeking ideation.

The study also explored the following overarching contextual psychosocial variables: caregivers' region (Amhara, Oromia, SNNPR, Tigray), residence (urban versus rural), malaria transmission zone (high versus low/no), age (15-24, 25-34, and 35-49 years old), education (none versus primary or higher), religion (Christian versus non-Christian), marital status (married or cohabiting versus not), and wealth quintile based on ownership of household assets (richest, richer, middle, poorer, poorest).

Access to ITNs within the household was defined as the number of bed nets per household member. Given the assumption that a bed net can be used by up to two people, a value of $\geq 0.5$ was defined as adequate ITN supply, while $<0.5$ was classified as inadequate. Exposure to health communication messages was assessed by asking whether caregivers had the Family Health Guide (FHG), a national 
health communication tool given to all families. FHG comprises more than 79 messages with cues to action and illustrations focusing on multiple health areas including malaria.

Additionally, a vulnerability index was assessed in the survey using four states the participant said they experienced in the last 12 months: (1) lacked adequate nutrition, (2) lacked shelter/house to stay in, (3) was unable to afford to send children to school, and (4) lacked sufficient money to buy medicines/medical treatment. Responses included never (coded as 1 ), rarely (coded as 2 ), sometimes (coded as 3), and often (coded as 4). We computed a composite score from the sum of the four responses. The vulnerability index was divided into two categories: non-vulnerable (score $\leq 7$ ) and vulnerable (8-16), with high scores indicating a greater level of poverty. Finally, the study included survey timing (baseline versus follow-up) as a contextual variable to account for temporal changes that might explain inter relationships between psychosocial factors and care-seeking.

Since we performed analysis on children under five with a fever in the two weeks preceding the survey, we explored any clustering effect that might occur with multiple children under five in the same household/caregiver. No evidence of clustering in the data (intraclass correlation $=0.015$ ) appeared. The study used chi-square, t-tests, and Analyses of Variance for bivariable tests of association and exploratory analysis, comparing characteristics of caregivers of febrile children versus those without fever and to compare psychosocial factors across the spectrum of care-seeking. We employed multivariable logistic regressions to explore psychosocial factors associated with both care-seeking and prompt care-seeking. Data management and analysis was performed using Stata software, version 16 (Stata Corporation, College Station, TX, USA) and Excel 2016 (Microsoft Corp, Seattle, WA, USA). We weighted the data using the svyset command in Stata to ensure the data was representative of the study population.

\section{Results}

\section{Description of study population}

As shown in Table 1, on average, caregivers were aged $25-34$ years old (53\%), had formal education (70\%), identified as Christian (64\%), and were married (95\%). While most caregivers resided in households not considered to be vulnerable (78\%), most households had inadequate mosquito nets $(87 \%)$. In addition, only few caregivers had the FHG (12\%). 
Table 1

Description of caregivers of children under five with and without fever in the study population $(\mathrm{N}=2453)$

\begin{tabular}{|c|c|c|c|c|c|c|c|}
\hline \multirow{2}{*}{$\begin{array}{l}\text { Caregiver } \\
\text { characteristics }\end{array}$} & \multicolumn{2}{|c|}{$\begin{array}{l}\text { Children with no Fever } \\
(N=1974)\end{array}$} & \multicolumn{2}{|c|}{$\begin{array}{l}\text { Children with Fever } \\
(\mathrm{N}=479)\end{array}$} & \multicolumn{2}{|c|}{$\begin{array}{l}\text { Total } \\
(\mathrm{N}=2453)\end{array}$} & \multirow[t]{2}{*}{$\begin{array}{l}\mathrm{P} \\
\text { value }\end{array}$} \\
\hline & No. & $\%$ & No. & $\%$ & No. & $\%$ & \\
\hline Region & & & & & & & 0.035 \\
\hline Amhara & 419 & 29 & 92 & 27 & 511 & 29 & \\
\hline Oromia & 593 & 36 & 105 & 31 & 698 & 35 & \\
\hline SNNPR & 496 & 28 & 140 & 34 & 636 & 29 & \\
\hline Tigray & 466 & 6 & 142 & 9 & 608 & 7 & \\
\hline $\begin{array}{l}\text { Malaria transmission } \\
\text { zone }\end{array}$ & & & & & & & 0.007 \\
\hline Free/Low & 810 & 43 & 139 & 35 & 949 & 41 & \\
\hline Moderate/High & 1164 & 57 & 340 & 65 & 1504 & 59 & \\
\hline Age & & & & & & & 0.018 \\
\hline $15-24$ & 372 & 19 & 79 & 17 & 451 & 19 & \\
\hline $25-34$ & 1052 & 54 & 232 & 48 & 1284 & 53 & \\
\hline $35-49$ & 550 & 27 & 168 & 35 & 718 & 29 & \\
\hline Education & & & & & & & 0.369 \\
\hline None & 1378 & 70 & 315 & 68 & 1693 & 70 & \\
\hline$\geq$ Primary & 596 & 30 & 164 & 32 & 760 & 30 & \\
\hline Religion & & & & & & & 0.845 \\
\hline Christian & 1306 & 64 & 331 & 64 & 1637 & 64 & \\
\hline Non-Christian & 668 & 36 & 148 & 36 & 816 & 36 & \\
\hline Marital status & & & & & & & 0.494 \\
\hline Not married & 96 & 5 & 31 & 6 & 127 & 5 & \\
\hline Married & 1877 & 95 & 448 & 94 & 2325 & 95 & \\
\hline Wealth Index & & & & & & & 0.113 \\
\hline Poorest & 579 & 26 & 155 & 27 & 734 & 26 & \\
\hline Poorer & 270 & 13 & 53 & 11 & 323 & 13 & \\
\hline
\end{tabular}




\begin{tabular}{|c|c|c|c|c|c|c|c|}
\hline \multirow{2}{*}{$\begin{array}{l}\text { Caregiver } \\
\text { characteristics }\end{array}$} & \multicolumn{2}{|c|}{$\begin{array}{l}\text { Children with no Fever } \\
(N=1974)\end{array}$} & \multicolumn{2}{|c|}{$\begin{array}{l}\text { Children with Fever } \\
(N=479)\end{array}$} & \multicolumn{2}{|c|}{$\begin{array}{l}\text { Total } \\
(\mathrm{N}=2453)\end{array}$} & \multirow[t]{2}{*}{$\begin{array}{l}\mathrm{P} \\
\text { value }\end{array}$} \\
\hline & No. & $\%$ & No. & $\%$ & No. & $\%$ & \\
\hline Middle & 380 & 20 & 105 & 24 & 485 & 20 & \\
\hline Richer & 360 & 20 & 71 & 15 & 431 & 20 & \\
\hline Richest & 385 & 21 & 95 & 23 & 480 & 21 & \\
\hline $\begin{array}{l}\text { Household has enough } \\
\text { nets }\end{array}$ & & & & & & & 0.912 \\
\hline No & 1686 & 87 & 408 & 87 & 2094 & 87 & \\
\hline Yes & 286 & 13 & 71 & 13 & 357 & 13 & \\
\hline Vulnerability index & & & & & & & 0.004 \\
\hline Not Vulnerable & 1607 & 80 & 346 & 73 & 1953 & 78 & \\
\hline Vulnerable & 367 & 20 & 133 & 27 & 500 & 22 & \\
\hline $\begin{array}{l}\text { Household owns family } \\
\text { health guide }\end{array}$ & & & & & & & 0.776 \\
\hline No & 1677 & 88 & 399 & 89 & 2076 & 88 & \\
\hline Yes & 297 & 12 & 80 & 11 & 377 & 12 & \\
\hline Survey timing & & & & & & & 0.767 \\
\hline Baseline (2016) & 1250 & 64 & 311 & 65 & 1561 & 64 & \\
\hline Follow up (2019) & 724 & 36 & 168 & 35 & 892 & 36 & \\
\hline
\end{tabular}

Caregivers' reports indicated the prevalence of fever among children under five in the two weeks preceding the survey was highest in SNNPR (34\%) and Oromia (31\%) regions but lowest in Tigray (9\%). Fever was much higher in the moderate and high malaria transmission zones (65\%), though still present in free or low transmission zones (35\%). Caregivers aged 15-24 years old (17\%) were less likely to report fever compared to older caregivers, both aged 25-34 (48\%) and 35-49 (35\%) years old. The presence of fever was significantly higher among caregivers in vulnerable households $(27 \%)$ compared to the overall population (22\%).

The prevalence of fever was not associated with the following caregiver and household characteristics: education, religion, marital status, ownership of the FHG, household wealth, and ITN supply.

\section{Spectrum of Care-seeking for Children with Fever}

Table 2 highlights the spectrum of care-seeking for children with fever. Overall, $45 \%$ of caregivers of children with fever sought care promptly while $23 \%$ delayed care-seeking and $32 \%$ sought no care. Care- 
seeking behavior differed significantly by some contextual psychosocial factors. Higher rates of prompt care-seeking were observed in Oromia (54\%) and SNNPR (47\%), compared with Amhara (33\%) and Tigray $(42 \%)$ regions. Caregivers' education significantly influenced care-seeking behavior. More than half (57\%) of caregivers who had formal education sought care promptly (only $18 \%$ delayed care-seeking while $24 \%$ sought no care). Meanwhile, only $39 \%$ of caregivers with no formal education sought care promptly ( $26 \%$ delayed care-seeking while $35 \%$ sought no care). 
Table 2

Spectrum of care-seeking and contextual psychosocial factors $(\mathrm{N}=479)$

\begin{tabular}{|c|c|c|c|c|c|c|c|}
\hline \multirow[t]{2}{*}{ Characteristics } & \multicolumn{2}{|c|}{ No care } & \multicolumn{2}{|c|}{ Delayed care } & \multicolumn{2}{|c|}{ Prompt care } & \multirow[t]{2}{*}{$P$ value } \\
\hline & No. & $\%$ & No. & $\%$ & No. & $\%$ & \\
\hline Total & 181 & 32 & 95 & 23 & 203 & 45 & $\mathrm{n} / \mathrm{a}$ \\
\hline Region & & & & & & & 0.001 \\
\hline Amhara & 44 & 46 & 18 & 21 & 30 & 33 & \\
\hline Oromia & 29 & 21 & 22 & 25 & 54 & 54 & \\
\hline SNNPR & 35 & 26 & 40 & 27 & 65 & 47 & \\
\hline Tigray & 73 & 46 & 15 & 11 & 54 & 42 & \\
\hline Malaria transmission zone & & & & & & & 0.648 \\
\hline Free/Low & 53 & 33 & 23 & 20 & 63 & 47 & \\
\hline Moderate/High & 128 & 31 & 72 & 25 & 140 & 44 & \\
\hline Age & & & & & & & 0.189 \\
\hline $15-24$ & 25 & 28 & 14 & 19 & 40 & 53 & \\
\hline $25-34$ & 87 & 31 & 41 & 21 & 104 & 48 & \\
\hline $35-49$ & 69 & 35 & 40 & 29 & 59 & 37 & \\
\hline Education & & & & & & & 0.005 \\
\hline None & 133 & 35 & 65 & 26 & 117 & 39 & \\
\hline$\geq$ Primary & 48 & 24 & 30 & 18 & 86 & 57 & \\
\hline Religion & & & & & & & 0.168 \\
\hline Christian & 134 & 35 & 64 & 25 & 133 & 41 & \\
\hline Non-Christian & 47 & 27 & 31 & 21 & 70 & 51 & \\
\hline Marital status & & & & & & & 0.432 \\
\hline Not married & 12 & 34 & 3 & 12 & 16 & 55 & \\
\hline Married & 169 & 32 & 97 & 24 & 187 & 44 & \\
\hline Wealth Index & & & & & & & 0.413 \\
\hline Poorest & 78 & 41 & 23 & 19 & 54 & 40 & \\
\hline Poorer & 21 & 37 & 11 & 26 & 21 & 38 & \\
\hline
\end{tabular}




\begin{tabular}{|llllllll|}
\hline Characteristics & \multicolumn{2}{l}{ No care } & \multicolumn{3}{l}{ Delayed care } & Prompt care & P value \\
\cline { 2 - 8 } & No. & $\%$ & No. & $\%$ & No. & $\%$ & \\
\hline Middle & 37 & 31 & 20 & 23 & 48 & 46 & \\
\hline Richer & 19 & 27 & 15 & 23 & 37 & 50 & \\
\hline Richest & 26 & 23 & 26 & 28 & 43 & 49 & \\
\hline Household has enough nets & & & & & & & 0.273 \\
\hline No & 158 & 33 & 81 & 24 & 169 & 43 & \\
\hline Yes & 23 & 23 & 14 & 22 & 34 & 55 & \\
\hline Vulnerability index & & & & & & & 0.103 \\
\hline Not Vulnerable & 133 & 31 & 76 & 26 & 137 & 42 & \\
\hline Vulnerable & 48 & 34 & 19 & 16 & 66 & 51 & \\
\hline Household owns family health guide & & & & & & & 0.235 \\
\hline No & 147 & 32 & 84 & 25 & 168 & 44 & \\
\hline Yes & 34 & 32 & 11 & 14 & 35 & 53 & \\
\hline Survey timing & & & & & & & 0.600 \\
\hline Baseline (2016) & 116 & 33 & 57 & 22 & 138 & 45 & \\
\hline Follow up (2019) & 65 & 30 & 38 & 26 & 65 & 44 & \\
\hline
\end{tabular}

Prompt care-seeking was slightly higher than average among caregivers who were aged 15-24 (53\%), unmarried $(55 \%)$ or in households with sufficient bed nets (55\%), but the differences were not significantly different.

\section{Ideational psychosocial factors related to care-seeking}

Ideational psychosocial factors explored included knowledge, self-efficacy, response efficacy, beliefs, decision making involvement and social support in the household. Table 3 shows the spectrum of careseeking and associated ideational psychosocial factors. While the majority (95\%) of caregivers were aware of malaria, only $52 \%$ knew malaria symptoms, $60 \%$ knew the cause of malaria and $24 \%$ knew measures to prevent malaria. Most caregivers had positive attitudes towards prompt care-seeking (90\%). In addition, most caregivers had positive perceptions related to malaria including perceived response efficacy for prompt care-seeking (96\%) and malaria prevention (88\%), perceived self-efficacy to seek care promptly (87\%) and prevent malaria (77\%). Many (70\%) caregivers reported involvement in decisionmaking, but few noted social support in the household from their partners (44\%). Overall, less than half $(44 \%)$ of caregivers possessed high care-seeking ideation. 
Page 14/25 
Table 3

Spectrum of care-seeking and ideational psychosocial factors ( $N=479)$

\begin{tabular}{lllllll} 
Characteristics & \multicolumn{2}{l}{$\begin{array}{l}\text { Total } \\
(\mathbf{N}=479)\end{array}$} & $\begin{array}{l}\text { No care } \\
(\mathbf{N}=181)\end{array}$ & $\begin{array}{l}\text { Delayed care } \\
(\mathbf{N}=95)\end{array}$ & $\begin{array}{l}\text { Prompt care } \\
(\mathrm{n}=203)\end{array}$ & P value \\
\hline No. $\%$ & No. $\%$ & No. $\%$ & No. & $\%$
\end{tabular}

Care-seeking ideational factors

Ever heard of malaria

0.952

$\begin{array}{lllllllll}\text { No } & 22 & 5 & 7 & 30 & 4 & 22 & 11 & 48 \\ \text { Yes } & 457 & 95 & 174 & 32 & 91 & 23 & 192 & 45\end{array}$

Knowledge of malaria symptoms

$\begin{array}{lllllllll}\text { Low } & 228 & 48 & 88 & 34 & 47 & 24 & 93 & 42 \\ \text { High } & 251 & 52 & 93 & 30 & 48 & 23 & 110 & 47\end{array}$

Knowledge of malaria cause

$\begin{array}{lllllllll}\text { No } & 188 & 40 & 78 & 35 & 38 & 25 & 72 & 40 \\ \text { Yes } & 291 & 60 & 103 & 30 & 57 & 22 & 131 & 48\end{array}$

Knowledge of malaria

prevention measures

$\begin{array}{lllllllll}\text { Low } & 379 & 76 & 151 & 32 & 74 & 24 & 154 & 44 \\ \text { High } & 100 & 24 & 30 & 31 & 21 & 21 & 49 & 48\end{array}$

Perceived self-efficacy for prompt care-seeking

$\begin{array}{lllllllll}\text { No } & 65 & 13 & 39 & 51 & 19 & 35 & 7 & 14 \\ \text { Yes } & 414 & 87 & 142 & 29 & 76 & 22 & 196 & 49\end{array}$

Perceived self-efficacy for malaria prevention

\begin{tabular}{|llllllllll|}
\hline No & 92 & 23 & 40 & 37 & 16 & 22 & 36 & 41 & \\
\hline Yes & 387 & 77 & 141 & 30 & 79 & 24 & 167 & 46 & \\
\hline $\begin{array}{l}\text { Perceived response efficacy of } \\
\text { prompt care seeking }\end{array}$ & & & & & & & & 0.514 \\
No & 15 & 4 & 7 & 37 & 5 & 33 & 3 & 29 & \\
Yes & 464 & 96 & 174 & 32 & 90 & 23 & 200 & 45 & \\
\hline
\end{tabular}




\begin{tabular}{|c|c|c|c|c|c|c|c|c|c|}
\hline \multirow[t]{2}{*}{ Characteristics } & \multicolumn{2}{|c|}{$\begin{array}{l}\text { Total } \\
(\mathrm{N}=479)\end{array}$} & \multicolumn{2}{|c|}{$\begin{array}{l}\text { No care } \\
(\mathrm{N}=181)\end{array}$} & \multicolumn{2}{|c|}{$\begin{array}{l}\text { Delayed care } \\
(\mathrm{N}=95)\end{array}$} & \multicolumn{2}{|c|}{$\begin{array}{l}\text { Prompt care } \\
(n=203)\end{array}$} & \multirow[t]{2}{*}{$P$ value } \\
\hline & No. & $\%$ & No. & $\%$ & No. & $\%$ & No. & $\%$ & \\
\hline $\begin{array}{l}\text { Perceived response efficacy of } \\
\text { malaria prevention }\end{array}$ & & & & & & & & & 0.020 \\
\hline No & 53 & 12 & 28 & 50 & 9 & 18 & 16 & 32 & \\
\hline Yes & 426 & 88 & 153 & 29 & 86 & 24 & 187 & 46 & \\
\hline $\begin{array}{l}\text { Positive attitudes toward } \\
\text { prompt care-seeking }\end{array}$ & & & & & & & & & 0.001 \\
\hline No & 41 & 10 & 24 & 54 & 12 & 31 & 5 & 15 & \\
\hline Yes & 438 & 90 & 157 & 29 & 83 & 23 & 198 & 48 & \\
\hline $\begin{array}{l}\text { Involvement in decision } \\
\text { making }\end{array}$ & & & & & & & & & 0.016 \\
\hline No & 135 & 30 & 46 & 29 & 37 & 33 & 52 & 38 & \\
\hline Yes & 344 & 70 & 135 & 33 & 58 & 19 & 151 & 48 & \\
\hline Social support in household & & & & & & & & & 0.797 \\
\hline No & 262 & 56 & 100 & 31 & 55 & 25 & 107 & 44 & \\
\hline Yes & 217 & 44 & 81 & 33 & 40 & 22 & 96 & 46 & \\
\hline $\begin{array}{l}\text { Perceived equitable gender } \\
\text { norms }\end{array}$ & & & & & & & & & 0.010 \\
\hline No & 404 & 86 & 163 & 34 & 81 & 24 & 160 & 42 & \\
\hline Yes & 75 & 14 & 18 & 17 & 14 & 18 & 43 & 65 & \\
\hline Overall care-seeking Ideation & & & & & & & & & 0.002 \\
\hline Low & 261 & 56 & 115 & 37 & 57 & 27 & 89 & 36 & \\
\hline High & 218 & 44 & 66 & 26 & 38 & 19 & 114 & 56 & \\
\hline
\end{tabular}

Specific ideational psychosocial factors significantly associated with care-seeking included self-efficacy for prompt care-seeking, response efficacy of malaria prevention, positive attitudes toward prompt careseeking, involvement in decision-making, and perceived equitable gender norms in the community. Specifically, caregivers with perceived self-efficacy for prompt care-seeking were more likely to seek care promptly (49\%), compared to those without perceived self-efficacy (14\%). Similarly, caregivers with perceived response efficacy of malaria prevention sought care promptly (46\%) compared to those without (32\%). Furthermore, $50 \%$ of those without perceived response efficacy did not seek any care. Caregivers with positive attitudes towards care-seeking also had higher rates of prompt care-seeking (48\%) compared to those without. In addition, $54 \%$ of those without positive attitudes sought no care for their 
children. Caregivers involved in household decision-making were more likely to seek care promptly (48\%) than those uninvolved (38\%), while caregivers who perceived equitable gender norms in their community had higher rates of prompt care-seeking (65\%) compared to those without these perceptions ( $42 \%)$.

Overall, the study observed significantly higher rates of prompt care-seeking (56\%) among caregivers with high ideation, compared to caregivers with lower levels of ideation (36\%).

\section{Inter-relationship between care-seeking ideational and contextual psychosocial factors with prompt care-seeking}

Table 4 highlights the inter-relationships between ideational and contextual psychosocial factors with prompt care-seeking. Contextual psychosocial factors positively associated with high care-seeking ideation included malaria transmission zone, age, and marital status. Specifically, while caregivers in SNNPR had reduced odds of a high care-seeking ideation (adjusted odds ratio (aOR): 0.39; $95 \%$ confidence interval (Cl): 0.19-0.77), caregivers in high transmission zones had increased odds of having high levels of care-seeking ideation (aOR: $1.85 ; 95 \% \mathrm{Cl}$ : 1.03-3.30). Older caregivers aged 25-34 years (aOR: $2.41 ; 95 \% \mathrm{Cl}: 1.32-4.38$ ) and 35-49 years (aOR: 2.04 (1.05-3.93) old had increased odds of a high care-seeking ideation compared to caregivers aged 15-24 years. In addition, caregivers with a primary education (aOR: $2.24 ; 95 \% \mathrm{Cl}: 1.42-3.55$ ) had increased odds of a high care-seeking ideation. 
Table 4

Inter-relationship between prompt care-seeking, ideational and contextual psychosocial factors $(\mathrm{N}=479)$

\begin{tabular}{llllllll}
\multicolumn{2}{l}{$\begin{array}{l}\text { High care-seeking } \\
\text { ideation (Prevalence = 44\%) }\end{array}$} & \multicolumn{4}{l}{$\begin{array}{l}\text { Prompt care-seeking } \\
\text { (Prevalence = 45\%) }\end{array}$} \\
\hline OR & $95 \% \mathrm{Cl}$ & aOR & $95 \% \mathrm{Cl}$ & OR & $\begin{array}{l}95 \% \\
\mathrm{Cl}\end{array}$ & aOR & $\begin{array}{l}95 \% \\
\mathrm{Cl}\end{array}$
\end{tabular}

Ideational psychosocial factors

Low care-seeking ideation

(reference)

$1.00 \mathrm{~N} / \mathrm{A} \quad 1.00 \quad \mathrm{~N} / \mathrm{A}$

High care-seeking ideation

$\begin{array}{llll}2.12 & 1.46- & 2.65 & 1.74- \\ & 3.06 & & 4.02\end{array}$

\section{Contextual psychosocial factors}

\section{Region}

Amhara (reference)

$1.00 \mathrm{~N} / \mathrm{A}$

$1.00 \mathrm{~N} / \mathrm{A}$

$1.00 \mathrm{~N} / \mathrm{A}$

$1.00 \mathrm{~N} / \mathrm{A}$

Oromia

0.40

$0.22-$

$0.54 \quad 0.25-$

2.19

1.13

1.23-

$2.99 \quad 1.40-$

0.72

0.39

0.19-

1.79

3.91

6.41

SNNPR

$0.72 \quad 0.42-$

0.77

$1.04-$

1.77

$0.86-$

1.22

$\begin{array}{ll}0.95 & 0.52- \\ & 1.75\end{array}$

1.27

3.10

3.65

Tigray

$\begin{array}{ll}1.24 & 0.73- \\ 2.09\end{array}$

$0.73-$

2.20

1.17

$0.61-$

2.25

\section{Malaria transmission zone}

No/low (reference)

$1.00 \mathrm{~N} / \mathrm{A}$

$1.00 \mathrm{~N} / \mathrm{A}$

$1.00 \mathrm{~N} / \mathrm{A}$

$1.00 \mathrm{~N} / \mathrm{A}$

High

$\begin{array}{ll}1.98 \quad 1.31- \\ & 2.99\end{array}$

1.85

1.03-

3.30

$0.84 \quad 0.57-$

$0.85 \quad 0.46-$

1.26

1.55

\section{Age in years}

$\begin{array}{lllllllll}15-24 \text { (reference) } & 1.00 & \text { N/A } & 1.00 & \text { N/A } & 1.00 & \text { N/A } & 1.00 & \text { N/A } \\ 25-34 & 1.58 & 0.94- & \mathbf{2 . 4 1} & \mathbf{1 . 3 2 -} & 0.79 & 0.48- & 0.64 & 0.36- \\ & & 2.66 & & \mathbf{4 . 3 8} & & 1.32 & & 1.15 \\ 35-49 & 1.29 & 0.74- & \mathbf{2 . 0 4} & \mathbf{1 . 0 5 -} & \mathbf{0 . 5 3} & \mathbf{0 . 3 1 -} & \mathbf{0 . 4 9} & \mathbf{0 . 2 6} \\ & & 2.22 & & \mathbf{3 . 9 3} & & \mathbf{0 . 9 1} & & \overline{\mathbf{0 . 9 5}}\end{array}$

\section{Education}

None (reference)

$1.00 \mathrm{~N} / \mathrm{A}$

$1.00 \mathrm{~N} / \mathrm{A}$

$1.00 \mathrm{~N} / \mathrm{A}$

$1.00 \mathrm{~N} / \mathrm{A}$

Primary or more

$\begin{array}{ll}1.99 \quad 1.36 \\ & 2.92\end{array}$

2.24

$1.42-$

3.55

1.87

$1.27-$

2.73

1.71

1.07-

2.72 
High care-seeking

ideation (Prevalence $=44 \%$ )
Prompt care-seeking

$($ Prevalence $=45 \%)$

\section{Religion}

$\begin{array}{lllllllll}\text { Christian (reference) } & 1.00 & \text { N/A } & 1.00 & \text { N/A } & 1.00 & \text { N/A } & 1.00 & \text { N/A } \\ \text { Non-Christian } & \mathbf{0 . 4 7} & \mathbf{0 . 3 2 -} & 0.79 & 0.45- & 1.34 & 0.90- & 0.93 & 0.53- \\ & & \mathbf{0 . 7 1} & & 1.37 & & 1.97 & & 1.65\end{array}$

\section{Marital status}

$\begin{array}{lllllllll}\text { Not married (reference) } & 1.00 & \mathrm{~N} / \mathrm{A} & 1.00 & \mathrm{~N} / \mathrm{A} & 1.00 & \mathrm{~N} / \mathrm{A} & 1.00 & \mathrm{~N} / \mathrm{A} \\ \text { Married } & 1.56 & 0.73- & 1.54 & 0.68- & 0.67 & 0.32- & 0.60 & 0.27- \\ & & 3.34 & & 3.49 & & 1.39 & & 1.33\end{array}$

\section{Wealth index}

$\begin{array}{lclllllll}\text { Poorest (reference) } & 1.00 & \text { N/A } & 1.00 & \text { N/A } & 1.00 & \text { N/A } & 1.00 & \text { N/A } \\ \text { Poorer } & 0.68 & 0.36- & 0.78 & 0.39- & 1.23 & 0.65- & 1.29 & 0.65- \\ & & 1.29 & & 1.54 & & 2.33 & & 2.57 \\ \text { Middle } & 0.81 & 0.49- & 1.00 & 0.57- & 1.58 & 0.95- & 1.41 & 0.79- \\ & & 1.34 & & 1.76 & & 2.61 & & 2.51 \\ \text { Richer } & 1.16 & 0.66- & 1.42 & 0.74- & \mathbf{2 . 0 4} & \mathbf{1 . 1 5 -} & \mathbf{2 . 0 8} & \mathbf{1 . 0 7 -} \\ & & 2.03 & & 2.72 & & \mathbf{3 . 6 0} & & \mathbf{4 . 0 2} \\ \text { Richest } & 1.01 & 0.61- & 1.44 & 0.74- & 1.55 & 0.92- & 1.29 & 0.65- \\ & & 1.69 & & 2.81 & & 2.61 & & 2.54\end{array}$

\section{Household has enough}

bed nets

$\begin{array}{lllllllll}\text { No (reference) } & 1.00 & \text { N/A } & 1.00 & \text { N/A } & 1.00 & \text { N/A } & 1.00 & \text { N/A } \\ \text { Yes } & 1.46 & 0.88- & 1.05 & 0.60- & 1.30 & 0.78- & 1.43 & 0.80- \\ & & 2.42 & & 1.83 & & 2.15 & & 2.54\end{array}$

\section{Vulnerability index}

$\begin{array}{llllllllll}\text { Not vulnerable } & 1.00 & \text { N/A } & 1.00 & \text { N/A } & 1.00 & \text { N/A } & 1.00 & \text { N/A } \\ \text { Vulnerable } & 0.73 & \begin{array}{l}0.48- \\ 1.09\end{array} & 0.86 & 0.55- & \mathbf{1 . 5 0} & \mathbf{1 . 0 0 -} & \mathbf{2 . 0 1} & \mathbf{1 . 2 8 -} \\ & & & 1.35 & & \mathbf{2 . 2 5} & & \mathbf{3 . 1 8}\end{array}$

\section{Household owns family} health guide

$\begin{array}{lllllllll}\text { No (reference) } & 1.00 & \text { N/A } & 1.00 & \text { N/A } & 1.00 & \text { N/A } & 1.00 & \text { N/A } \\ \text { Yes } & 1.04 & 0.64- & 0.75 & 0.44- & 1.07 & 0.66- & 1.47 & 0.85- \\ & & 1.68 & & 1.27 & & 1.74 & & 2.53\end{array}$




\begin{tabular}{|c|c|c|c|c|c|c|c|c|}
\hline \multirow[b]{2}{*}{ Baseline (2016) } & \multicolumn{4}{|c|}{$\begin{array}{l}\text { High care-seeking } \\
\text { ideation }(\text { Prevalence }=44 \% \text { ) }\end{array}$} & \multicolumn{4}{|c|}{$\begin{array}{l}\text { Prompt care-seeking } \\
\text { (Prevalence }=45 \% \text { ) }\end{array}$} \\
\hline & 1.00 & N/A & 1.00 & N/A & 1.00 & N/A & 1.00 & $\mathrm{~N} / \mathrm{A}$ \\
\hline Follow up (2019) & 1.06 & $\begin{array}{l}0.73- \\
1.54\end{array}$ & 0.86 & $\begin{array}{l}0.56- \\
1.31\end{array}$ & 0.79 & $\begin{array}{l}0.54- \\
1.16\end{array}$ & 0.75 & $\begin{array}{l}0.49- \\
1.15\end{array}$ \\
\hline
\end{tabular}

Caregivers with a high care-seeking ideation had increased odds of prompt care-seeking (aOR: 2.65; $95 \%$ Cl: 1.74-4.02) compared to their counterparts with low care-seeking ideation. Contextual factors associated with prompt care-seeking include residence in Oromia region (aOR: 2.99; 95\% Cl: 1.40-6.41), being educated (aOR: $1.71 ; 95 \% \mathrm{Cl}: 1.07-2.72$ ), and residence in a vulnerable household (aOR: $2.01 ; 95 \%$ Cl: 1.28-3.18). On the other hand, older caregivers aged 35-49 years old had lower odds of prompt careseeking (aOR: 0.49; 95\% Cl: 0.26-0.95).

\section{Discussion}

\section{Principal findings}

Among this rural Ethiopian population, prompt care-seeking rates were low but positively associated with both ideational and contextual psychosocial factors occurring at the caregiver level. The study found an association between high care-seeking ideation and higher rates of prompt care-seeking. Specific ideational factors of note in this setting included perceived self-efficacy, response efficacy, attitudes toward prompt care-seeking, and involvement in household decision-making. Contextual psychosocial factors associated with influencing prompt care-seeking in rural Ethiopia included region of residence, education, and household vulnerability. This study reported similar rates of care-seeking ideation and behavior across the baseline and follow-up surveys. However, analysis of the follow-up survey data by exposure to the $\mathrm{C} 4 \mathrm{H}$ program interventions demonstrated significantly higher rates of prompt careseeking, knowledge, and perceived efficacy among caregivers exposed to the program interventions.

\section{Comparison with other studies}

This study is of significance as it is one of few studies exploring factors associated with prompt careseeking for children under five with fever in rural Ethiopia. The few existing previous studies have focused on the sole effect of psychosocial factors such as knowledge and perceptions [19] or contextual factors such as residence[20]. This study employs a larger perspective and elucidates the complementarity of both psychosocial and structural factors associated with malaria related behavior.

\section{Study implications}

Disparities in access to health services have been well documented using frameworks incorporating quality, geographic accessibility, availability, financial accessibility, and acceptability of services[21]. Study findings can inform relevant behavior change, structural and research interventions to reverse this trend in rural Ethiopia. This study demonstrated the overall role of psychosocial ideational factors. A key 
premise behind the ideation model is that people do not ordinarily take action, especially new action, until they have gained sufficient knowledge about it and its consequences, until they have a positive attitude toward it, and until they have talked to others about it and feel right about it[13].

Communication can directly influence such cognitive, emotional, and social factors of ideation separately, as well as jointly as these ideational factors often are interdependent and often occur simultaneously. Considering this, social and behavior change interventions should employ messaging that not only improves communities' knowledge about prompt care-seeking and its benefits but also promotes a positive attitude about prompt care-seeking, generates conversation and decision-making regarding prompt care-seeking, and enables communities to feel right about seeking care promptly. Behavior change approaches should aim to promote supportive norms within the community and remove barriers to caregivers' self-efficacy and response efficacy regarding prompt care-seeking and other malaria related behavior.

To sustain behavior change related to health care utilization within communities, complementary approaches are needed at the health provider level. In Ethiopia, challenges in access to health care have been mitigated using community health workers. To ensure interventions that bring about positive change, community workers in the study regions need to be empowered with relevant technical and interpersonal communication skills to continue to deliver high quality malaria testing and treatment services.

Intended interventions should leverage existing knowledge of factors that influence health worker performance. In particular, limited supervision and support, lack of recognition and appreciation of accomplishments, limited opportunities for professional advancement, few professional support networks, and lack of financial incentives have negatively impacted health workers' performance[13]. Non-material factors like health workers' self-image and acceptance by the community and their supervisors were found to positively impact health worker performance and retention[22, 23].

The role of contextual and ideational factors suggests interventions should employ a holistic approach to health and quality of life, not just focus on malaria. This is of critical importance, as educational achievement and gender equality norms remain key factors in rural Ethiopia. Holistic approaches should employ a multi-sectoral lens and combine health, education, and gender empowerment interventions to improve the lives of community members. Investing in women, and, more specifically, girl's education, has several positive effects on children, women, and communities at large, combating poverty and fostering economic growth[24, 25]. At the heart of achieving gender equality is the education of girls and women and the removal of barriers to education and opportunities for their advancement.

\section{Strengths and limitations}

A key strength of the study is the use of a theory-driven, comprehensive exploration of psychosocial factors specific to a high-risk population. We expect that our study findings might be generalizable to similar rural contexts in sub-Saharan Africa. However, some study limitations include its cross-sectional 
design, which limits the ability to make causal inferences. The use of self-reported data from multiple survey rounds may be limited by recall or social desirability bias. While the study employed the ideation model as part of its theoretical underpinnings, some aspects of this theory such as social influence, spousal/partner communication, and personal advocacy were not explored in this study. In addition, the study did not ask about health provider- or facility-level factors that could influence care-seeking, such as either perceived quality of care or stock out of commodities. Future research should seek to use prospective studies to validate findings with more complete measures of the ideational constructs.

\section{Conclusion}

This study identified psychosocial factors among female caregivers of children under five with fever in rural Ethiopia. Structural factors included caregivers' level of education while ideational factors included caregivers' self-efficacy and response efficacy, attitudes related to prompt care-seeking, involvement in decision-making, and perceptions of gender equitable norms in the community. Such factors should be accounted for when designing and implementing multi-sectoral interventions at community level.

\section{Abbreviations}

aOR: Adjusted odds ratio

C4H: Communication for Health

Cl: Confidence interval

EA: Enumeration area

FHG: Family Health Guide

ITN: Insecticide-treated net

NMCEP: Ethiopia's National Malaria Control and Elimination Program

PPS: Probability proportionate to size

RDT: Rapid diagnostic testing

SBCC: Social and behavior change communication

SNNP: Southern Nations, Nationalities, and Peoples Region

USAID: United States Agency for International Development

\section{Declarations}




\section{Ethical approval and consent to participate}

The study received ethical approval from the Ethiopian Public Health Institute ethical review committee, Addis Ababa, Ethiopia, and the ethical review board of the Bloomberg School of Public Health, Johns Hopkins University, Baltimore, MD, USA. (JHSPH IRB \# 00007138 and EPHI-IRB-173-2019). All respondents provided written informed consent prior to participating in the survey. All methods were performed in accordance with the relevant guidelines and regulations in accordance with the Declaration of Helsinki.

\section{Consent for publication}

Not applicable

\section{Availability of data and materials}

The datasets used and analyzed during the current study are available from the corresponding author on reasonable request.

\section{Competing interests}

The authors declare that they have no competing interests.

\section{Funding}

This work is made possible by the support of the American people through the United States Agency for International Development (USAID) under the Breakthrough ACTION Cooperative Agreement \#AID-OAA-A17-00017. The funders had no role in study design, data collection and analysis, decision to publish, or preparation of the manuscript.

\section{Authors' contributions}

$\mathrm{BO}, \mathrm{HT}$, and NK conceptualized the study, analyzed the data, and drafted the manuscript. All co-authors assisted with interpretation of the results and critically edited and reviewed this manuscript. All authors read and approved the final manuscript.

\section{Acknowledgements}


The authors would like to thank Kevin Griffith and Jon Eric Tongren from the U.S. President's Malaria Initiative for their comments on earlier drafts of this manuscript, as well as Rebecca Pickard at Breakthrough ACTION for her assistance with editing and submission. We would like to thank the support of the American people through USAID under the Breakthrough ACTION Cooperative Agreement \#AIDOAA-A-17-00017. USAID had no role in study design, data collection and analysis, decision to publish, or preparation of the manuscript.

\section{References}

1. World Health Organization (WHO). World malaria report 2020: 20 years of global progress and challenges. Geneva: WHO; 2020.

2. Ethiopia Ministry of Health (MoH). National Malaria Elimination Strategic Plan: 2021-2025. Addis Ababa, Ethiopia: $\mathrm{MoH} ; 2020$.

3. Ethiopian Public Health Instititue. Ethiopia National Malaria Indicator Survey 2015. Addis Ababa, Ethiopia MoH; 2016.

4. VandenBos GR. APA dictionary of psychology. Washington, DC: American Psychological Association; 2007.

5. Auerbach MV, Lobel M, Cannella DT. Psychosocial correlates of health-promoting and healthimpairing behaviors in pregnancy. J Psychosom Obstet Gynaecol. 2014;35(3):76-83.

6. Park CL, Gaffey AE. Relationships between psychosocial factors and health behavior change in cancer survivors: an integrative review. Ann Behav Med. 2007;34(2):115-34.

7. Thomas K, Nilsson E, Festin K, Henriksson P, Lowén M, Löf M, Kristenson, M. Associations of psychosocial factors with multiple health behaviors: A population-based study of middle-aged men and women. Int J Environ Res Public Health. 2020;17(4):1239. doi: 10.3390/ijerph17041239.

8. Birhanu Z, Abebe L, Sudhakar M, Dissanayake G, Yihdego YY, Alemayehu G, Yewhalaw, D. Malaria related perceptions, care seeking after onset of fever and anti-malarial drug use in malaria endemic settings of southwest Ethiopia. PLoS One. 2016;11(8):e0160234. doi:

10.1371/journal.pone.0160234.

9. Tesfahunegn A, Zenebe D, Addisu A. Determinants of malaria treatment delay in northwestern zone of Tigray region, Northern Ethiopia, 2018. Malar J. 2019;18(1):358.

10. Tiruneh M, Gebregergs GB, Birhanu D. Determinants of delay in seeking treatment among malaria patients in Dera district, NorthWest Ethiopia: a case control study. Afr Health Sci. 2018;18(3):552-9.

11. Workineh B, Mekonnen FA. Early treatment-seeking behaviour for malaria in febrile patients in northwest Ethiopia. Malaria J. 2018;17(1):1-8.

12. Mitiku I, Assefa A. Caregivers' perception of malaria and treatment-seeking behaviour for under five children in Mandura District, West Ethiopia: a cross-sectional study. Malaria J. 2017;16(1):1-10.

13. Kincaid DL. Mass media, ideation, and behavior:A longitudinal analysis of contraceptive change in the Philippines. Commun Res. 2000;27(6):723-63. 
14. Kincaid DL. Social networks, ideation, and contraceptive behavior in Bangladesh: a longitudinal analysis. Soc Sci Med. 2000;50(2):215-31.

15. Olapeju B, Adams C, Hunter G, Wilson S, Simpson J, Mitchum L, et al. Malaria prevention and care seeking among gold miners in Guyana. PloS One. 2020;15(12):e0244454.

16. Storey JD, Babalola SO, Ricotta EE, Fox KA, Toso M, Lewicky N, Koenker H. Associations between ideational variables and bed net use in Madagascar, Mali, and Nigeria. BMC Public Health. 2018;18(1):484. doi: 10.1186/s12889-018-5372-2

17. Do M, Babalola S, Awantang G, Toso M, Lewicky N, Tompsett A. Associations between malariarelated ideational factors and care-seeking behavior for fever among children under five in Mali, Nigeria, and Madagascar. PloS One. 2018;13(1):e0191079.

18. Bandura A. Self-efficacy: toward a unifying theory of behavioral change. Psychol Rev. 1977 Mar;84(2):191.

19. Birhanu Z, Yihdego YY-e, Yewhalaw D. Caretakers' understanding of malaria, use of insecticide treated net and care seeking-behavior for febrile illness of their children in Ethiopia. BMC Infect Dis. 2017;17(1):1-16.

20. Gelaw YA, Biks GA, Alene KA. Effect of residence on mothers' health care seeking behavior for common childhood illness in Northwest Ethiopia: a community based comparative cross-sectional study. BMC Res Notes. 2014;7(1):1-8.

21. Peters DH, Garg A, Bloom G, Walker DG, Brieger WR, Hafizur Rahman M. Poverty and access to health care in developing countries. Ann NY Acad Sci. 2008;1136(1):161-71.

22. Arora N, Hanson K, Spicer N, Estifanos AS, Keraga DW, Welearegay AT, et al. Understanding the importance of non-material factors in retaining community health workers in low-income settings: a qualitative case-study in Ethiopia. BMJ Open. 2020;10(10):e037989. doi: 10.1136/bmjopen-2020037989.

23. Mbemba GIC, Gagnon M-P, Hamelin-Brabant L. Factors influencing recruitment and retention of healthcare workers in rural and remote areas in developed and developing countries: an overview. Journal Public Health Afr. 2016;7(2).

24. Ember H. Benefits of investing in girl education. Idosr J. Current Issues Soc. Sci. 2020; 26(1):27-32.

25. Hailu MF. Examining the role of Girl Effect in contributing to positive education ideologies for girls in Ethiopia. Gend Educ. 2019;31(8):986-99.

\section{Supplementary Files}

This is a list of supplementary files associated with this preprint. Click to download.

- SupplementalTables.docx 